\title{
Retraction Note to: Prediction of urban pollution particles and nutritional safety monitoring of protein food based on image processing
}

\author{
Wei Ling ${ }^{1}$
}

Published online: 3 November 2021

(c) Saudi Society for Geosciences 2021

\section{Retraction Note to: Arabian Journal of Geosciences} (2021) 14: 1773

https://doi.org/10.1007/s12517-021-08075-2

The Editor-in-Chief and the Publisher have retracted this article because the content of this article is nonsensical. The peer review process was not carried out in accordance with the Publisher's peer review policy. The author has not responded to correspondence regarding this retraction.

The original article can be found online at https://doi.org/10.1007/ s12517-021-08075-2.

Wei Ling

lunwen975@126.com

1 College of Life Sciences, Langfang Normal University,

Langfang 065000, Hebei, China 